\title{
NEONATAL MORTALITY AND NEURODEVELOPMENTAL OUTCOME OF VERY LOW BIRTH WEIGHT (VLBW) NEWBORNS ATTENDING A RURAL TERTIARY CARE HOSPITAL, PREDICTED BY CLINICAL RISK INDEX FOR BABIES SCORE II (CRIBS II)
}

\author{
Kausik Patra1 , Balai Chandra Karmakar²
}

${ }^{1}$ Ex-Postgraduate Trainee, Department of Paediatric Medicine, North Bengal Medical College and Hospital, Darjeeling, West Bengal, India.

${ }^{2}$ Associate Professor, Department of Paediatric Medicine, North Bengal Medical College and Hospital, Darjeeling, West Bengal, India. ABSTRACT

\section{BACKGROUND}

Mortality and various neuro-developmental sequelae among very low birth weight babies (VLBW) are a common problem in Indian scenario. Most of them are delayed diagnosed and there is no enough research work available regarding magnitude and pattern of disability in Indian scenario. Data which is available from developed countries is not reflecting the real picture of developing countries. In contrast to western population, our hands are bound by various problems including poor nutrition of mother during antenatal period, anaemia, poor hygiene, infection, unhealthy environment and inadequate health-care infrastructure. Several studies have reported high incidence of growth failure and poor neurological outcome during infancy and childhood. There have been a few studies from India, reporting growth and neurodevelopment of low birth weight infants. We wanted to assess the efficacy of CRIBS II as a tool for assessing the mortality and long-term neuro-developmental outcome of VLBW babies.

\section{METHODS}

This prospective cohort study included 143 VLBW babies admitted in Sick New Born Care Unit (SNCU) of North Bengal Medical College \& Hospital, Darjeeling, West Bengal from June 2016 to August 2017 and discharged babies were followed up.

\section{RESULTS}

A total of 143 neonates were studied at SNCU. Among them, $82(57.3 \%)$ were male and 61(42.7\%) were female. Birth weight ranged from 500 to 1500 grams with a mean of $1199.6 \pm 244.14$ and the median was $1240 \mathrm{gm}$. CRIB II score ranged from 1-18 with mean of $8.021 \pm 3.883$, and median of $7.73 .4 \% .105$ out of 143 were discharged alive. Significant positive correlations were found among birth weight, gestational age, temperature, excess base, and progressive increase in mortality with increasing CRIB II score $(p<0.001)$. Adverse neonatal outcome associated with CRIB II score $\geq 10$. Cut off value of CRIB II score $(>10)$ at which maximum sensitivity of $97.5 \%$ and specificity of $50 \%$ is 9.5 for predicting mortality of VLBW babies. The value under the ROC curve was 0.986 (95 \% CI: $0.000-1.000)$ with a standard error of 0.0029 .

\section{CONCLUSIONS}

CRIB II score was found to be a very good tool for VLBW babies with regard to mortality and neuro-developmental assessment. It is easily applicable and can replace the traditional models as a predictor of neonatal outcome.

HOW TO CITE THIS ARTICLE: Patra K, Karmakar BC. Neonatal mortality and neurodevelopmental outcome of very low birth weight (VLBW) newborns attending a rural tertiary care hospital, predicted by clinical risk index for babies score II (CRIBS II). J. Evolution Med. Dent. Sci. 2019;8(19):1521-1527, DOI: 10.14260/jemds/2019/338

\section{BACKGROUND}

Globally, prematurity is the leading cause of neonatal death (babies $<4$ weeks) and now the second leading cause of death after pneumonia in children under five years of age. In low-income settings, half of the babies born at 32 weeks die due to a lack of feasible, cost-effective care, such as warmth, breast feeding support, and basic care for infections and breathing difficulties. In high-income countries, almost all of these babies survive.(1)

'Financial or Other Competing Interest': None.

Submission 26-02-2019, Peer Review 24-04-2019,

Acceptance 30-04-2019, Published 13-05-2019.

Corresponding Author:

Dr. Balai Chandra Karmakar,

30 H Harey Krista Sett Lane,

P. S. Sinthi, Kolkata-700050,

West Bengal,

India.

E-mail: balaikarmakar75@gmail.com

DOI: $10.14260 /$ jemds $/ 2019 / 338$

\section{(c) $(1)(-)$}

More than 20 million infants worldwide, representing $15.5 \%$ of all births are born with low birth weight, $95.6 \%$ of them in developing countries. The number of low birth weight babies in developing countries $(16.5 \%)$ is more than double in developed countries (7\%). In India it is estimated that incidence of LBW is about $30 \%$. (Resourced by DHS on 1999 and reanalysed on June 2003).(2) In 2005 it was 28\% and in 2010 it was nearly $20 \%$ of new-borns were LBW. The North-east zone has the lowest prevalence of LBW while the north zone has the highest. $(3,4)$

Nearly $24 \%$ or one in four children born prematurely across the globe in 2010 were from India. Around one million children die each year due to complications of preterm birth. Significant progress has been made in the care of premature infants, but not in reducing the prevalence of preterm birth.(5) In 2010, an estimated $32 \cdot 4$ million infants were born small for gestational age in low-income and middle-income countries ( $27 \%$ of live births), of whom 10.6 million infants were born at term and low birth weight. Of 18 million lowbirth weight babies, 59\% were term-SGA and $41 \%$ were preterm-SGA. Two-thirds of small-for-gestational-age infants 
were born in Asia (17.4 million in south Asia). Preterm-SGA babies totalled to $2 \cdot 8$ million births in low-income and middle-income countries. Most small-for-gestational-age infants were born in India, Pakistan, Nigeria, and Bangladesh.(6)

Therefore in past years various scoring system have been developed to predict neonatal morbidity and mortality and these neonatal scores have been developed in order to assume a more accurate evaluation. Unfortunately mortality rates, even if are risk adjusted, can no longer be the only index of the performance of neonatal intensive care unit. During last two decades various scoring system for assuming neonatal mortality risk were introduced as follows:

The national institute of health neonatal network model,(7)SNAP (Score for Neonatal Acute Physiology),(8)SNAPPE(Score for Neonatal Acute Physiology-Perinatal Extension)(9)and CRIBS (Clinical Risk Index for Babies).(10)Then SNAP-II (Simplified New-born Illness Severity and Mortality Risk Score) and CRIBS II(An Update of CRIBS) ware developed later in NICU and introduced as robust indices of neonatal risk, to predict mortality and morbidity in new-borns. ${ }^{(10,11)}$

CRIB II scoring system has five variables: (i) Birth weight (ii) Gestational age (iii) Base deficit (iv) Temperature on admission and (v) Sex.

It is a risk index for newborn weighing less than 1500 grams. The score is divided according to gender and weight are compared with gestational age. The range of score for weight compared with gestational age in male is $0-15$ and in female is $0-14$ and for temperature the score is $0-5$ and for base excess 0-7. At the end the scores are totalled. Better prognosis with lower scores attained the best favourable results with score of one.

\section{METHODS}

\section{Settings and Design}

A Prospective cohort study among 143 VLBW babies admitted in Sick New Born Care Unit (SNCU) of North Bengal Medical College \& Hospital, Darjeeling, West Bengal from June 2016 to August 2017 and discharged babies were followed up.

\section{Inclusion Criteria}

All preterm newborn of both sexes admitted in SNCU 23 to 32 weeks of gestational age and birth weight $<1500$ grams.

\section{Exclusion Criteria}

All preterm newborn Less than 23 weeks of gestation, Birth weight $<500$ grams, Gross congenital malformation, genetic disorder, delivery room death, admission after 12 hours of birth.

\section{Study Tools}

The study was conducted by using Measuring tape, Torch, Cubes, Percussion hammer, Infantometer, DDST chart, Growth chart, Proforma, SPSS V 20, EpiCalc 2000 v 1.2 statistical software and Analyse-it for method validation in MS excel ultimate edition.

\section{Data Collection}

1. Obstetrical history of mother for time of birth, gestational age in week calculated from the first day of last menstrual Period (LMP).

2. Neonatal Data-

a) Gestational age by obstetrical ultrasonography and Expanded New Ballard Score where LMP is unknown.

b) Gender and Birth weight by digital weighing scale.

c) Base excess on admission by arterial blood gas analysis.

d) Temperature (Celsius) on admission by digital thermometer.

e) Anthropometry (height, weight, head circumference) using WHO growth chart/foetalinfant growth chart/CDC growth chart accordingly.

f) Developmental and neurological score using DDST chart and standard neurological examination procedure.

g) Ophthalmological and BERA examination report.

Growth and developmental assessment and neurological examination on follow up of discharged babies at $1 \mathrm{st}$, 3rd, 6th, 9th, 12th months.

All the parameters along with the Gender of baby were assigned scores according to CRIBS II. The final CRIB II score (ranged from 0 to 27) was obtained by the arithmetic sum of the individual scores. The scores were further classified into four levels as follows; Level 1:0 to 5, Level 2:6 to 10, Level $3: 11$ to 15 , Level 4 above 15.(12)

\section{Statistical Analysis}

Independent $t$ test and Pearson's chi-square test were used to analyse the data. The analysis of specificity and sensitivity of the studied variables for mortality prediction was carried out through Receiver Operating Characteristics (ROC) curves, and the areas under the curves (AUC) were compared to define the differences with statistical significance with selection of the most suitable cut-off point of each parameter with the best sensitivity, specificity, positive predictive value (PPV), negative predictive value (NPV) and overall accuracy. All tests were tailed with $\mathrm{p}$ value $<0.05$ as significant and performed by SPSS v 20, Chicago. Pearson correlation was used for calculation between CRIB II score and Predicted Death Rate.

\section{RESULTS}

143 babies were studied, $82(57.3 \%)$ were males and $61(42.7 \%)$ were females. Non-survivors represented 38 (26.6\%) while survivors represented 105 (73.4\%). According to CRIB II score babies were classified into 4 groups: 


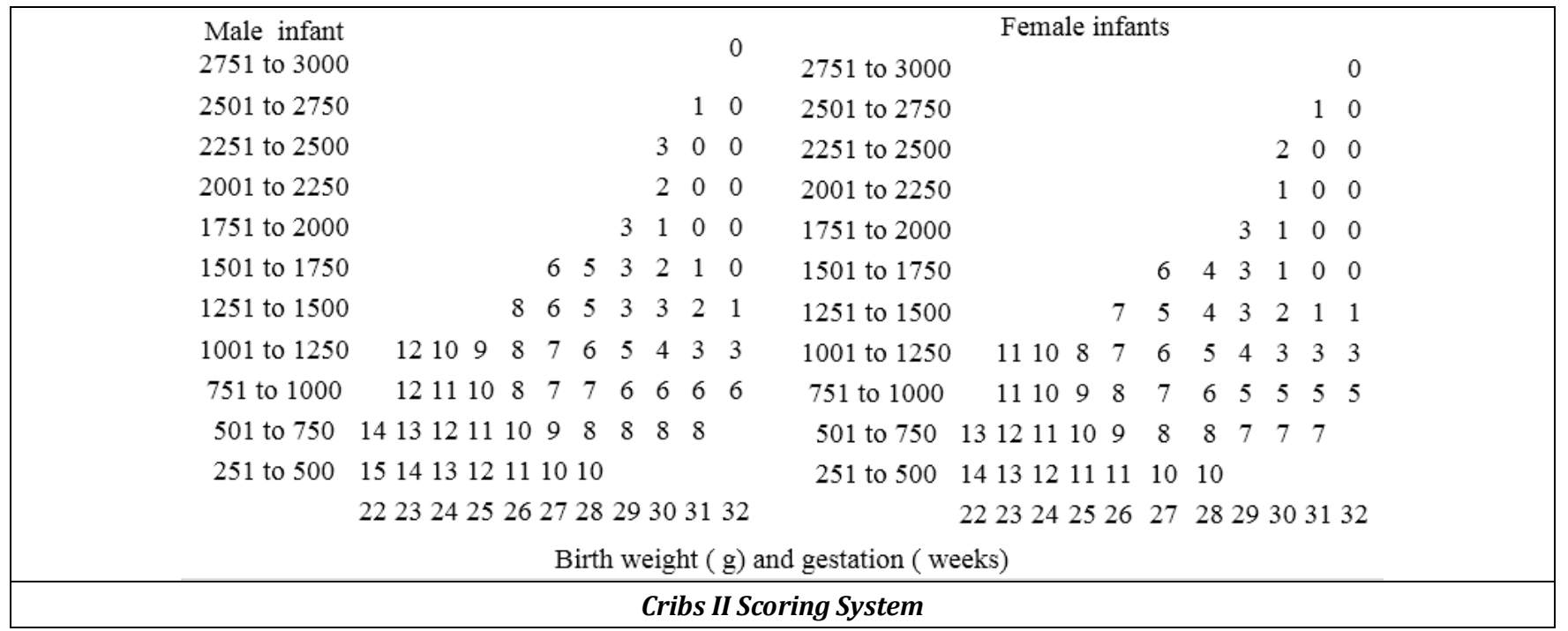

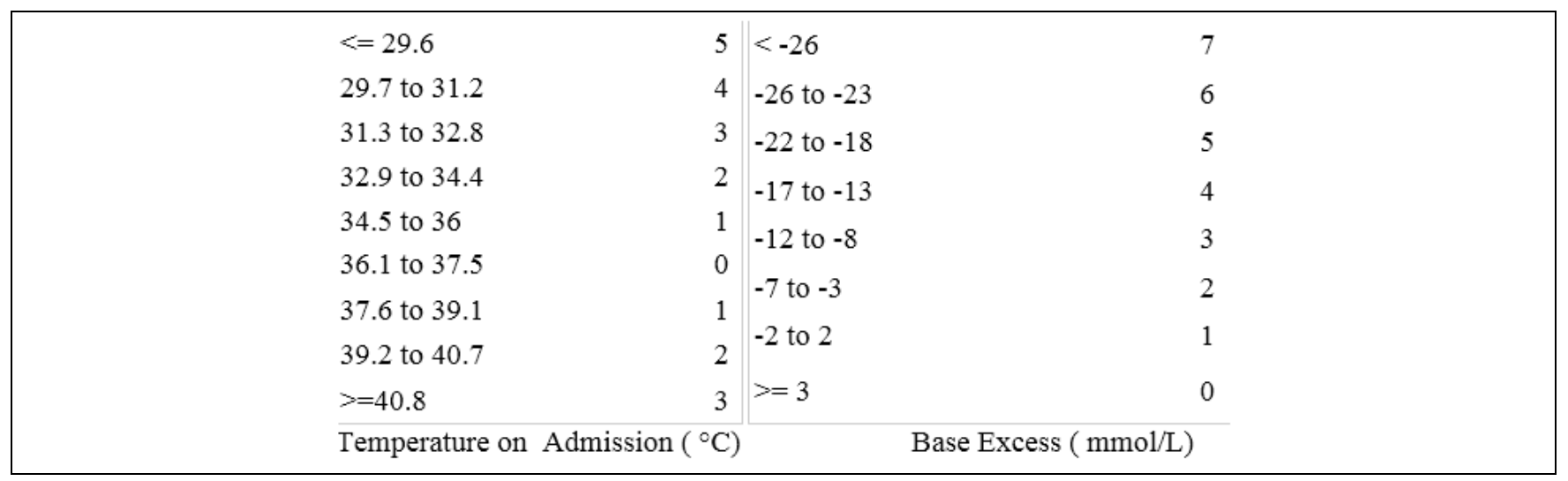

\begin{tabular}{|c|c|c|c|c|c|c|c|}
\hline & Distribs & amples & & Out & & & \\
\hline CRIB II Score Level & accordi & al Score & Disc & $(\mathrm{N}=105)$ & & $\mathrm{N}=38$ ) & p value \\
\hline Level I (0-5) & 52 & $36.4 \%$ & 52 & $49.5 \%$ & 0 & 0 & \\
\hline Level II (6-10) & 56 & $39.2 \%$ & 53 & $50.5 \%$ & 3 & $7.9 \%$ & $<0 \Omega 01$ \\
\hline Level III (11-15) & 27 & $18.9 \%$ & 0 & 0 & 27 & $71.1 \%$ & $<0.001$ \\
\hline Level IV (>15) & 8 & $5.5 \%$ & 0 & 0 & 8 & $21.1 \%$ & \\
\hline $\begin{array}{r}\text { Table 1. The Mean T } \\
\text { (Mean } \pm \text { SD) was } 1 \\
(\text { Mean } \pm \text { SD) was } 29.6 \\
\text { SD) was } 33.54 \pm 1.61\end{array}$ & $\begin{array}{l}\text { al Score } \\
9.6 \pm 244 \\
2.032 W \\
\text { with } R a\end{array}$ & $\begin{array}{l}\text { D) was } 8 \\
\text { ith Ran } \\
\text { Range } \\
7 \text { C Canc } \\
\text { h Rang }\end{array}$ & $\begin{array}{l}32 \mathrm{We} \\
\mathrm{Med} \\
0 \text { to }+\end{array}$ & $\begin{array}{l}\text { Range } 3 \\
\text { and the I } \\
\text { the Med } \\
34^{\circ} \mathrm{C} . \mathrm{Tl} \\
\text { the Medi }\end{array}$ & $\begin{array}{l}\text { as } 3 \\
\text { in } B \\
s-4\end{array}$ & $\begin{array}{l}\text { an was } \\
\text { gm. Th } \\
\text { s. The I } \\
\text { cess (M }\end{array}$ & $\begin{array}{l}\text { n Birth } \\
\text { stationa } \\
\text { erature } \\
\text { as }-5.68\end{array}$ \\
\hline
\end{tabular}

\begin{tabular}{|c|c|c|c|}
\hline Parameter/Variables & & & Description n= 143 \\
\hline Gender & Number & $\%$ & \multirow{3}{*}{ Male mortality is higher than females. } \\
\hline Male & 82 & 57.3 & \\
\hline Female & 61 & 42.7 & \\
\hline Birth Weight (in gm) & Number & $\%$ & \multirow{6}{*}{$\begin{array}{l}\text { The mean birth weight (Mean } \pm \text { SD) was } 1199.6 \pm 244.14 \text { gm } \\
\text { with range } 580-1490 \text { gm and the median was } 1240 \text { grams and } \\
\text { mean gestational age (Mean } \pm \text { SD) was } 29.65 \pm 2.032 \text { weeks } \\
\text { with range } 24-32 \text { weeks and the median was } 30 \text { weeks. }\end{array}$} \\
\hline $500-\leq 1000$ & 34 & 23.8 & \\
\hline $1001-\leq 1500$ & 109 & 76.2 & \\
\hline Gestational Age (weeks) & Number & $\%$ & \\
\hline $24-\leq 28$ & 37 & 25.9 & \\
\hline $29-\leq 32$ & 106 & 74.1 & \\
\hline Temperature (in ${ }^{0} \mathrm{C}$ ) & Number & $\%$ & \multirow{5}{*}{$\begin{array}{c}\text { The mean temperature (Mean } \pm \mathrm{SD}) \text { was } 33.54 \pm 1.61^{\circ} \mathrm{C} \text { with } \\
\text { range } 30-37^{\circ} \mathrm{C} \text { and the median was } 34^{\circ} \mathrm{C} .\end{array}$} \\
\hline $30.0-32.0$ & 34 & 23.8 & \\
\hline $32.1-34.0$ & 60 & 42 & \\
\hline $34.1-36.0$ & 48 & 33.6 & \\
\hline $36.1-37.0$ & 1 & 0.7 & \\
\hline Base excess (mmol/L) & Number & $\%$ & \multirow{2}{*}{$\begin{array}{l}\text { The mean base excess (Mean } \pm \text { SD) was }-5.68 \pm 4.37 \text { with range } \\
\qquad-20 \text { to }+2.0 \text { and the median was }-4.5 \text {. }\end{array}$} \\
\hline-20.4 to -10.0 & 20 & 14 & \\
\hline
\end{tabular}




\begin{tabular}{|c|c|c|c|}
\hline-9.9 to 0.0 & 117 & 81.8 & \\
\hline 0.1 to 2.0 & 6 & 4.2 & \\
\hline \multicolumn{4}{|c|}{ Distribution of Samples According to Score for BW \& GA } \\
\hline Score for BW \& GA & Number & $\%$ & \multirow{4}{*}{$\begin{array}{l}\text { The mean score for } B W \& \text { GA (Mean } \pm \text { SD) was } 3.78 \pm 2.71 \text { with } \\
\text { range } 1-12 \text { and the median was } 3 .\end{array}$} \\
\hline $1-4$ & 90 & 62.9 & \\
\hline $5-8$ & 45 & 31.5 & \\
\hline $9-12$ & 8 & 5.6 & \\
\hline \multicolumn{4}{|c|}{ Distribution of Samples According to Score for Temperature } \\
\hline Score for temperature & Number & $\%$ & \multirow{3}{*}{$\begin{array}{l}\text { The mean score for temperature (Mean } \pm \text { SD) was } 2.11 \pm 0.93 \\
\text { with range } 0-4 \text { and the median was } 2\end{array}$} \\
\hline $0-2$ & 106 & 74.1 & \\
\hline $3-4$ & 37 & 25.9 & \\
\hline \multicolumn{4}{|c|}{ Distribution of Samples According to Score for BE } \\
\hline Score for BE & Number & $\%$ & \multirow{3}{*}{$\begin{array}{l}\text { The mean score for } \mathrm{BE}(\mathrm{Mean} \pm \mathrm{SD}) \text { was } 2.15 \pm 0.91 \text { with range } \\
1-5 \text { and the median was } 2\end{array}$} \\
\hline $1-2$ & 108 & 75.5 & \\
\hline $3-5$ & 35 & 24.5 & \\
\hline \multicolumn{4}{|c|}{ Table 2. Descriptive Data of The Studied Neonates } \\
\hline
\end{tabular}

\begin{tabular}{|c|c|c|c|c|c|}
\hline Parameter/variables & Outcomes & $\mathbf{N}$ & Mean & Std. Dev & P value \\
\hline \multirow{2}{*}{ Birthweight (in gms) } & Discharged & 105 & 1306.2 & 155.42 & \multirow{2}{*}{$<0.001$} \\
\hline & Expired & 38 & 900 & 194.01 & \\
\hline \multirow{2}{*}{ Gestational age (in weeks) } & Discharged & 105 & 30.56 & 1.229 & \multirow{2}{*}{$<0.001$} \\
\hline & Expired & 38 & 27.08 & 1.605 & \\
\hline \multirow{2}{*}{ Score for BW GA } & Discharged & 105 & 2.63 & 1.71 & \multirow{2}{*}{$<0.001$} \\
\hline & Expired & 38 & 7.0 & 2.4 & \\
\hline \multirow{2}{*}{ Temperature at admission $\left({ }^{\circ} \mathrm{C}\right)$} & Discharged & 105 & 34.26 & 0.981 & \multirow{2}{*}{$<0.001$} \\
\hline & Expired & 38 & 31.52 & 1.278 & \\
\hline \multirow{2}{*}{ Score for Temp } & Discharged & 105 & 1.69 & 0.58 & \multirow{2}{*}{$<0.001$} \\
\hline & Expired & 38 & 3.3 & 0.7 & \\
\hline \multirow{2}{*}{ Base excess (mmol/L) } & Discharged & 105 & -3.66 & 2.0 & \multirow{2}{*}{$<0.001$} \\
\hline & Expired & 38 & -11.3 & 4.26 & \\
\hline \multirow{2}{*}{ Score for BE } & Discharged & 105 & 1.75 & 0.5 & \multirow{2}{*}{$<0.001$} \\
\hline & Expired & 38 & 3.27 & 0.87 & \\
\hline
\end{tabular}

Table 3. Comparison of Parameters of Crib II Scores Between Discharged Alive and Expired

\begin{tabular}{|c|c|c|}
\hline CRIB II Score & Pearson Correlation & Outcomes \\
\hline \multirow{2}{*}{ Total CRIB II score } & Pearson Correlation & $0.823^{* *}$ \\
\cline { 2 - 3 } & Sig. (2-tailed) & 143 \\
\cline { 2 - 3 } Predicted Death Rate & $\mathrm{N}$ & 0.001 \\
\cline { 2 - 3 } & Pearson Correlation & $<19^{* *}$ \\
\cline { 2 - 3 } Table 4. Pearson Correlation was Statistically Significant with Positive Correlation Between Higher Total CRIB II Score and \\
Predicted Death Rate (\%) i.e. Higher Score was Associated with High Predicted Death Rate Values. \\
\hline \multicolumn{2}{|c}{ **. Correlation is significant at the 0.01 level (2-tailed). } \\
\hline
\end{tabular}

\begin{tabular}{|c|c|c|c|c|c|c|}
\hline Variables & Cut-off Point & Sensitivity & Specificity & PPV & NPV & Accuracy \\
\hline CRIB II Score & $\geq 10$ & $97.37 \%$ & $97.14 \%$ & $92.50 \%$ & $99.03 \%$ & $97.20 \%$ \\
\hline GA & $\leq 28$ & $76.32 \%$ & $92.38 \%$ & $78.38 \%$ & $91.51 \%$ & $88.11 \%$ \\
\hline Birth Weight & $\leq 1000$ & $73.68 \%$ & $94.29 \%$ & $82.35 \%$ & $90.82 \%$ & $88.81 \%$ \\
\hline BW \& GA & $>4$ & $86.84 \%$ & $80.95 \%$ & $62.26 \%$ & $94.44 \%$ & $82.52 \%$ \\
\hline Temperature & $>2$ & $84.21 \%$ & $95.24 \%$ & $86.49 \%$ & $94.34 \%$ & $92.31 \%$ \\
\hline Score for BE & $>2$ & $84.21 \%$ & $97.14 \%$ & $91.43 \%$ & $94.44 \%$ & $93.71 \%$ \\
\hline
\end{tabular}

Table 4a. Shows Screening Analysis of CRIB II Score, Gestational Age, Birth Weight BW \& GA, Temperature and Score for BE in Predicting Mortality Using the Most Suitable Cut-Off Point.

Chi-square $\left(\chi^{2}\right)$ test performed among different variables viz total CRIB II score ( $\chi^{2}=123.56$; $\left.\mathrm{p}=0.0000001\right)$, Score for BW \& GA ( $\left.\chi^{2}=54.91 ; \mathrm{p}=0.0000001\right)$, Score for temperature $\left(\chi^{2}=91.70 ; \mathrm{p}=0.0000001\right)$ and Score for $\mathrm{BE}\left(\chi^{2}=99.67 ; \mathrm{p}=0.0000001\right)$ and showed significant association between score and adverse outcome $(\mathrm{p}<0.01)$. The risk of death was more for total score $\geq 10$, score for BW \& GA $>4$, Score for temperature $>2$ and Score for BE $>2$. 


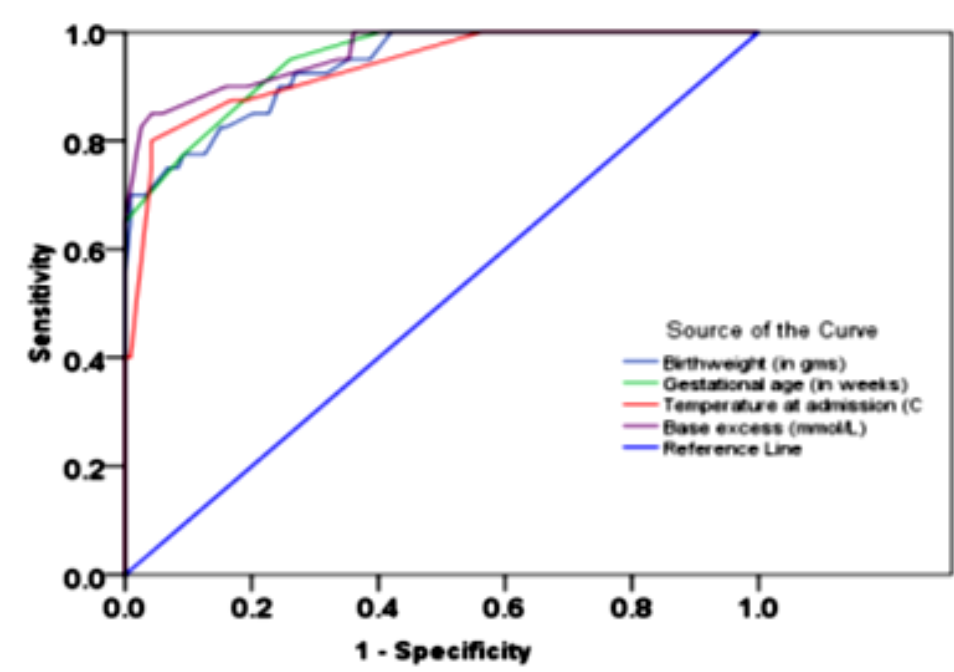

Figure 1. ROC curves of CRIB II Score and different parameters used in the score. With decreasing age, weight, temperature, and excess base, the mortality increased. Highest value of Area Under Curve (AUC) is seen with total score followed by score for temperature.

\begin{tabular}{|c|c|c|c|c|c|c|}
\hline \multirow{2}{*}{\multicolumn{2}{|c|}{ Growth Parameters }} & \multicolumn{4}{|c|}{ Total CRIB II score } & \multirow{2}{*}{ p Value } \\
\hline & & \multirow{2}{*}{$\begin{array}{l}\text { Mean } \\
7.346\end{array}$} & \multirow{2}{*}{$\begin{array}{c}\text { S.D } \\
1.765\end{array}$} & \multirow{2}{*}{$\frac{\text { Minimum }}{4}$} & \multirow{2}{*}{$\begin{array}{c}\text { Maximum } \\
10\end{array}$} & \\
\hline \multirow{2}{*}{ Weight for age ( $<-2 \mathrm{Z}$ Score) } & Yes & & & & & \multirow{2}{*}{$<0.001$} \\
\hline & No & 5.615 & 1.752 & 3 & 9 & \\
\hline \multirow{2}{*}{ Length for age ( $<-2 \mathrm{Z}$ score) } & Yes & 7.543 & 1.559 & 4 & 10 & \multirow{2}{*}{$<0.001$} \\
\hline & No & 5.298 & 1.597 & 3 & 9 & \\
\hline \multirow{2}{*}{ Weight for length (<-2 Z Score) } & Yes & 7.346 & 1.765 & 4 & 10 & \multirow{2}{*}{$<0.001$} \\
\hline & No & 5.615 & 1.752 & 3 & 9 & \\
\hline \multirow{2}{*}{ Head circumference for-age $(<-2 \mathrm{Z}$ score $)$} & Yes & 8.923 & 1.44 & 5 & 10 & \multirow{2}{*}{$<0.001$} \\
\hline & No & 5.423 & 1.608 & 3 & 9 & \\
\hline \multirow{2}{*}{ Head circumference $(\mathrm{cm})$} & $\leq 40$ & 7.87 & 1.486 & 6 & 10 & \multirow{2}{*}{$<0.001$} \\
\hline & $>40$ & 5.531 & 1.681 & 3 & 9 & \\
\hline \multirow{2}{*}{ Weight (kg) } & $\leq 7$ & 6.906 & 1.89 & 4 & 10 & \multirow{2}{*}{$<0.001$} \\
\hline & $>7$ & 5.667 & 1.792 & 3 & 9 & \\
\hline \multirow{2}{*}{ Length $(\mathrm{cm})$} & $\leq 70$ & 7.543 & 1.559 & 4 & 10 & \multirow{2}{*}{$<0.001$} \\
\hline & $>70$ & 5.29 & 1.591 & 3 & 9 & \\
\hline
\end{tabular}

Table 5. Showing correlation of different growth parameters with total CRIBS II score which shows good statistically correlation with a $p$ value $<0.05$.

\begin{tabular}{|c|c|c|c|c|c|}
\hline \multicolumn{5}{|c|}{ Total CRIB II Score } & \multirow{2}{*}{ p Value } \\
\hline & Mean & S.D. & Minimum & Maximum & \\
\hline \multicolumn{6}{|c|}{ Developmental Delay } \\
\hline Yes & 8.21 & 1.197 & 5 & 10 & \multirow{2}{*}{$<0.001$} \\
\hline No & 5.25 & 1.434 & 3 & 9 & \\
\hline \multicolumn{6}{|c|}{ Cerebral Palsy } \\
\hline Yes & 9.00 & 1.069 & 7 & 10 & \multirow{2}{*}{$<0.001$} \\
\hline No & 5.8 & 1.745 & 3 & 9 & \\
\hline \multicolumn{6}{|c|}{ Visual Abnormality } \\
\hline Yes & 8.8 & 0.919 & 7 & 10 & \multirow{2}{*}{$<0.001$} \\
\hline No & 5.76 & 1.745 & 3 & 10 & \\
\hline \multicolumn{6}{|c|}{ Absent ABR } \\
\hline Yes & 8.308 & 1.251 & 6 & 10 & \multirow{2}{*}{$<0.001$} \\
\hline No & 5.725 & 1.758 & 3 & 10 & \\
\hline
\end{tabular}

Table 6. Showing correlations of Total CRIB II Score with parameters of neuro-developmental delay like developmental delay, cerebral palsy, visual abnormality, absent ABR. All showing good correlations which is statistically significant $(p<0.001)$

\section{DISCUSSION}

Premature births are outnumbered by males with higher susceptibility of mortality (13). This finding is consistent with our study where male to female cases were 1.3:1 respectively, with higher mortality in males. A useful and simple method of risk-adjustment is important to ensure accurate assessment for quality care of newborn (14). Our study revealed positive associations between the gestational age, the birth weight temperature, base excess and the mortality; the lower the gestational age, birth weight the higher the mortality that was 
proved to be statistically significant $(\mathrm{p}<0.001)$. Survivors had a mean CRIB II score of less than non-survivors. Cut off value of CRIB score at which maximum sensitivity of $97.5 \%$ and specificity of $50 \%$ is 9.5 for predicting mortality of VLBW babies. Similar results were obtained by Ezz-Eldin ZM et al,(15) Jafrashteh A et al,(16) Jasik BM et al(17)and Heidarzadeh $M$ et al(18)

The value under the ROC curve was 0.986 (95 \% CI: 0.000 - 1.000) with a standard error of 0.0029. The curve is deviated upwards and to the right, so that it is located in the upper right corner of the graph that means as sensitivity decreases, it is not followed by loss of specificity. Higher scores correlated well with mortality. Therefore, CRIB II scoring turns out to be a reliable discriminative test. Compared to birth weight and gestational age, CRIB II score showed better calibration to predict neonatal mortality. This is in accordance with other studies like Ezz-Eldin et al (15) and Jasic BM et al.(17)

\section{Growth Outcome}

This study showed incidence of moderate to severe growth retardation ( $<-2 \mathrm{Z}$ score) like wasting $25.7 \%$, stunting $34.3 \%$, under nutrition $25.7 \%$ and microcephaly $24.8 \%$ among total study population which is comparable with Pradip k. Sharma et al,(19) and Modi et al, (20) study but microcephaly is about $15 \%$ more in our study that was due to socioeconomic factors, and significant postnatal morbidities, lack of detailed nutritional history and parental heights and small sample size.

This study also showed that AGA babies had microcephaly $14.8 \%$, stunting $24.7 \%$, wasting $14.8 \%$, under nutrition $14.8 \%$ in comparable with SGA babies it were $58.3 \%, 66.7 \%, 62.5 \%$ and $62.5 \%$ for SGA respectively and considerable differences between mean $\mathrm{Z}$ score (weight for age, weight for length, length for age, and head circumference for age) in two groups of population $(\mathrm{P}<0.05)$ which was consistent with observation done by Ane C. Westerberg et al(21) that Very low birth weight infants showed catch-up growth during the first year, but their weight and length remained less than full-term peers. Growth deficiencies were more pronounced among infants subjected to early growth restriction, despite increased catch-up growth. Pradip k. Sharma et al, (19) also shown the similar growth difference between VLBW SGA and AGA children.

\section{Neurodevelopment}

This study showed major neurological abnormalities are Developmental delay (isolated delay but no CP) 32.4\%, Cerebral palsy (CP) 7.6\%, Deafness $12.4 \%$, Blindness and/ or ROP $9.5 \%$ and more with higher CRIB II score that is comparable with study done by HoJJ et al (22) to estimate the prevalence and pattern of neuro-developmental handicap at 2 years of age in very low birth weight infants (VLBW) admitted in 1993 to a level 3 Malaysian nursery. Functionally $23.3 \%$ of the study group had mild handicap, $1.3 \%$ moderate, $2.5 \%$ severe, $2.5 \%$ multiply severe and $70.2 \%$ were normal. Most of western literature (Procianoy RS, Koch MS et al,(23) Gutbrod T et al,(24) Gabriel J Escobar et al and few eastern literature (Modi et al,(20) Pradip k. Sharma et al,(19) Mukhopadhyay $\mathrm{K}$ et al(25) showed the incidence of neurodevelopmental abnormality is lower in comparison to our study. Though the incidence of, hearing and visual abnormality is higher in our study, developmental delay and cerebral palsy is quite comparable, that, might be due to high rate of post-natal morbidity in VLBW babies and sample size is too small in compare to those studies.

\section{Limitations of The Study}

This study was done in small sample size $(n=143)$ with one year follow up period so we might miss some delayed neurodevelopmental sequelae. Parental height was not taken into consideration during stunting calculation.

\section{CONCLUSIONS}

CRIB II score proved to be a good tool for neonatal assessment and for predicting neonatal mortality and neurodevelopmental outcome among Indian neonates. It should be implemented as an essential component of routine care to all neonates admitted to SNCUs.

\section{Ethical Considerations}

The study was approved by of North Bengal Medical College \& Hospital, Darjeeling, West Bengal Ethics Committee. Written consent was taken from the parents of the involved neonates.

\section{REFERENCES}

[1] Low birth weight: country, regional and global estimates.

http://www.childinfo.org/files/low_birthweight_from EYY.pdf:

[2] Volpe JJ. Neurobiology of periventricular leukomalacia in the premature infant. Pediatr Res 2001;50(5):55362.

[3] Bharati P, Pal M, Bandyopadhyay M, et al. Prevalence and causes of low birth weight in India. Malays J Nutr 2011;17(3):301-13.

[4] Maternal and child survival, march 2012, by UNICEF http://www.childinfo.org/files/maternal/DI\%20Profi le\%20-\%20India.pdf

[5] Goldenberg RL, Culhane JF, Iams JD, et al Epidemiology and causes of preterm birth. Lancet 2008;371(9606):75-84

[6] Lee AC, Katz J, Blencowe H, et al. National and regional estimates of term and preterm babies born small for gestational age in 138 low-income and middle-income countries in 2010. The Lancet Global Health 2013;1(1):e26-e36.

[7] Horbar JD, Onnstad L, Wright E. Predicting mortality risk for infants weighing 501-1500 grams at birth. Crit Care Med 1993;21:12-8.

[8] Richardson DK, Gray JE, McCormic MC, et al. Score for neonatal acute physiologic severity index for neonatal intensive care. Pediatrics 1993;91(3):617-23.

[9] Richardson DK, Phibbs CS, Gray JE, et al. Birth weight and illness severity: independent predictors of neonatal mortality. Pediatrics 1993;91(5):969-75.

[10] International Neonatal Network. The CRIB (Clinical risk Index for babies) score: a tool for assessing initial neonatal risk and comparing performance of neonatal intensive care units. Lancet 1993;342(8865):193-8.

[11] Dorling JS, Field DJ, Manktelow B. Neonatal disease severity scoring systems. Arch Dis Child Fetal Neonatal Ed 2005;90(1):F11-6. 
[12] Brito AS, Matsuo T, Gonzalez MR, et al. CRIB score, birth weight and gestational age in neonatal mortality risk evaluation. Rev Saude Publica 2003;37(5):597602.

[13] Zeitlin J, Saurel-Cubizolles MJ, De Mouzon J, et al. Fetal sex and preterm birth: are males at greater risk? Hum Reprod 2002;17(10):2762-8.

[14] Parry G, Tucker J, Tarnow-Mordi W, et al. CRIB II: an update of the clinical risk index for babies score. Lancet 2003;361(9371):1789-91.

[15] Ezz-Eldin ZM, Hamid TAA, Youssef MRL, et al. Clinical Risk Index for Babies (CRIB II) scoring system in prediction of mortality in premature babies. Journal of Clinical and Diagnostic Research 2015;9(6):SC08SC11.

[16] Jafrasteh A. Clinical Risk Index for Neonates II score for the prediction of mortality risk in premature neonates with very low birth weight. World Family Medicine 2017;15(8):183-7. DOI: 10.5742/MEWFM.2017.93074.

[17] SindičićDessardo N, Jašić M, Dessardo S, et al. CRIB II score versus gestational age and birth weight in preterm infant mortality prediction: who will win the bet? Signavitae: Journal for Intesive Care and Emergency Medicine 2016;11(1):172-81.

[18] Heidarzadeh M, Ghorbani F, Dastgiri S. Prediction value of CRIB-II in outcome of preterm and low birth weight infants: a prospective cohort study. International Journal of Pediatrics 2016;4(4):1583-9.
[19] Sharma PK, Sankar MJ, Sapra S, et al. Growth and Neurosensory outcomes of preterm very low birth weight infants at 18 months of corrected age. Indian Journal of Pediatr 2011;78(12):1445-90.

[20] Modi M, Saluja S, Kler N, et al. Growth and neurodevelopmental outcome of VLBW infants at 1 year corrected age. Indian Pediatrics 2013;50(6):5737.

[21] Westerberg AC, Henriksen C, Ellingvåg A, et al. First year growth among very low birth weight infants. Acta Paediatrica 2010;99(4):556-62.

[22] Ho JJ, Amar HS, Mohan AJ, et al. Neurodevelopmental outcome of very low birth weight babies admitted to a Malaysian nursery. Journal of Paediatrics and Child Health 1999;35(2):175-80.

[23] Procianoy RS, Koch MS, Silveira RC. Neurodevelopmental outcome of appropriate and small for gestational age very low birth weight infants. J Child Neurol 2009;24(7):788-94.

[24] Gutbrod T, Wolke D, Soehne B, et al. Effects of gestation and birth weight on the growth and development of very low birth weight small for gestational age infants: a matched group comparison. Arch Dis Child Fetal Neonatal Ed 2000;82(3):F208F14.

[25] Mukhopadhyay K, Malhi P, Mahajan R, et al. Neurodevelopmental and behavioral outcome of very low birth weight babies at corrected age of 2 years. Indian J Pediatr 2010;77(9):963-7. 